\title{
pH and thermoresponsive comb-type grafted hydrogels based on polyethylene glycol diglycidyl ether and monoamino/diamino terminated jeffamines: synthesis, characterization and physicochemical properties
}

\begin{abstract}
Ahmet ERDEM 1* (D)
${ }^{1}$ Kocaeli University, Faculty of Technology, Department of Biomedical Engineering, Umuttepe Yerleşkesi 41001-Kocaeli. Turkey
\end{abstract}

\begin{abstract}
In the present study, the synthesis of thermo- and $\mathrm{pH}$-sensitive comb-type grafted hydrogels based on polyetheramine was performed using polyethylene glycol diglycidyl ether [PEGDGE] as the activator. Monoamino terminated Jeffamine ${ }^{\circledR}$ M2005 was used as the polyether to incorporate the hydrophobic and thermo-sensitive character in the copolymer, while diamino terminated Jeffamine ${ }^{\circledR}$ ED600 was used as the crosslinker to initiate the amineepoxy ring-opening reaction. These polyethylene glycol [PEG]-polypropylene glycol [PPG] hydrogels present $\mathrm{pH}$ responsive properties and thermo-sensitivity due to the presence of cationic functional groups and the Jeffamine moieties, respectively. Fourier-transform infrared (FTIR) spectroscopy and swelling behavior at different $\mathrm{pH}[2-10]$ and temperatures $\left[4-50{ }^{\circ} \mathrm{C}\right]$ were applied to examine the physicochemical properties of the hydrogels. The volume-phase transition temperature [VPTT] of the hydrogels was determined based on PPG content and pH of the solution. The physicochemical features of the hydrogels depended on the Jeffamine used and the ratio of Jeffamine units introduced. The maximum swelling capacity of the hydrogels as a function of time was determined at $4{ }^{\circ} \mathrm{C}$ and $\mathrm{pH} 5$, while the optimum deswelling capacity was obtained at $40{ }^{\circ} \mathrm{C}$ and $\mathrm{pH}$ 7.4. Results showed that the dual responsive PEG-PPG based hydrogels may be suitable for potential application as drug delivery system sensors.
\end{abstract}

\section{Article info \\ History:}

Received: 21.05.2020

Accepted: 15.09 .2020

Keywords:

Hydrogels,

Thermo-response,

$\mathrm{pH}$ response,

Swelling and

deswelling kinetics,

Polyethylene glycol.

\section{Introduction}

Stimuli responsive polymeric materials have received great attention over the last years, due to their interesting features with respect to different applications in the field of biomedicine, pharmacy and biotechnology. Generally, these polymeric materials are widely represented by hydrogels composed of either three-dimensional homo or copolymer crosslinked network [1]. These hydrogels' behavior is mainly based on their structural properties as well as environmental conditions. Over the last decades, hydrogels with environmentally responsive properties have been largely applied in smart material research. This class of hydrogels showd dramatic volume change in respect to different stimuli such as temperature, $\mathrm{pH}$, ionic activity, magnetic field, electrical, UV or visible light $[2,3]$. Thanks to this volume change character, also known as volume phase transition [VPT], various applications such as controlled drug delivery, tissue engineering, catalysts, etc. have been widely developed. Amongst all, temperature and $\mathrm{pH}$ responsive hydrogels have been extensively investigated attributed to their important physicochemical characteristics. In essence, derivatives of poly[N-isopropylacrylamide] [4] and poly[acrylic acid] [5] have proven to be the most used polymers in the preparation of thermo- and $\mathrm{pH}$ sensitive hydrogels, respectively. In addition, some investigated reports on crosslinked polyethylene glycol [PEG]// polypropylene glycol [PPG] hydrogels have demonstrated to possess temperature responsive properties [6-8]. The interaction between hydrophobic PPG and water molecules tends to show significantly temperature-dependent [9]. On the other hand, PEG, in comparison to other standard polymers, has an exceptional character where is phase separation over a critical point that relies on molar weight with increasing temperature [10].

Different forms of PEG and PPG such as di- and triblock copolymers also known commercially as pluronic or poloxamers are one of the most widely researched topics, attributed to their thermo-sensitive 
properties particularly in the field of controlled drug delivery and tissue engineering [11-13], paints, coatings and cosmetic formulations [14, 15]. In general, the synthesis of PEG-PPG crosslinked hydrogels has been mostly achieved using different reactive end groups of methacrylate $[16,17]$ and acrylate[18, 19] via free radical polymerization. However, this technique being air-sensitive has mostly been performed under controlled conditions in closed small-scale environments [20]. Thus, polycondensation and polyaddition polymerization reactions have proven to be the most widely used alternatives for the preparation of such hydrogels $[6$, 8], considering these reaction methods are not particularly sensitive to water, oxygen or impurity. Moreover, these polymerization reactions are widely applied in the production of industrial epoxy resin by reacting diepoxides with di- or tri-amines. Recently, amino terminated PEG and PPG polymers under the trade name Jeffamine ${ }^{\circledR}$ series, manufactured by Hunstsman have demonstrated to be ideal not only for the production of epoxy resins, but also in the synthesis of epoxy-amine based hydrogel [21]. Krakovsky et al. in a recent study prepared elastic epoxy based hydrogels by reacting Bisphenol A propoxylate diglycidyl ether with $\alpha$, $\omega$-diamino terminated Jeffamine ED2003 and ED600 [22]. In another study, Ribeles et al. investigated the thermal behavior of prepared Jeffamine ED2003 based hydrogels [23]. Also, Krakovsky et al. reported the synthesis of an epoxy network based on hydrophobic Jeffamine D series and polyethylene glycol bis[glycidyl ether] [PEGDGE] by analyzing their thermal transitional behaviors [20]. Recently, Anghelache et al. investigated the preparation of thermo-responsive hydrogels that were formed via the reaction of diamino terminated PPG and PEGDGE. Results showed that the volume phase transition was mainly dependent on the PEG/PPG ratio [6].

To date, the synthesis of such hydrogels is not limited solely to the use of diamino functional Jeffamine ${ }^{\circledR}$ ED and $\mathrm{D}$ series, but monoamino functional Jeffamine [Jeffamine M2005] has also demonstrated efficiency in the synthesis of temperature sensitive hydrogels. Typically, this functional Jeffamine ${ }^{\circledR}$ M2005 composed of monoamino terminated polyoxyethylene-block-polyoxypropylene [POE-POP] has been used in the functionalization of polysaccharides to form comb-type grafted thermoresponsive hydrogels [24, 25]. Normal types of temperature sensitive PEG / PPG based hydrogels with different structure have been extensively prepared. [6, 20, 22, 23]. However, in terms of fast response with respect to the stimuli responsiveness, one of the useful ways to improve response rates is via the adaptation of the hydrogel's structure at molecular level by grafting on the backbone of the polymers [17, 18]. In our previous studies, we prepared and compared PEG-PPG based normal- and comb-type grafted hydrogels and investigated their fast response rate to $\mathrm{pH}$ and temperature. Results depicted comb-type grafted hydrogels with the fastest response rates [26]. In addition, the volume phase transition temperature [VPTT] of the hydrogels depended mostly on the PEGPPG ratio [6, 8]. In this study, PEG-PPG based thermoand $\mathrm{pH}$ sensitive comb-type grafted cationic hydrogels were successfully prepared via amine-epoxy ring opening reaction by varying PPG ratio. The effects of grafted PPG content, swelling and deswelling capacity as a function time as well as solubility fractions of the hydrogels were analyzed systematically at varying temperatures and $\mathrm{pH}$ conditions. In addition, the VPTT changes of hydrogels were investigated following the difference in PPG content and solution $\mathrm{pH}$. Accordingly, it was observed that PPG ratio is vital in achieving efficient thermo-responsive hydrogels with rapid response and low solubility. The proposed novel comb-type cationic hydrogels show great potential for applications in various fields such as drug delivery, actuators, and smart sensors.

\section{Experimental}

\subsection{Materials}

In the preparation of the epoxy networks, $\alpha, \omega$-diamino terminated polyoxypropylene-block-polyoxyethyleneblock-polyoxypropylene [Jeffamine ED600] and monoamino terminated polyoxyethylene-blockpolyoxypropylene [Jeffamine M2005] of average molecular weights 528 and $2090 \mathrm{~g} / \mathrm{mol}$, respectively, were supplied by Hunstman [Texas, USA]. Polyethylene glycol bis[glycidyl ether] [PEGDGE] of average molecular weight $500 \mathrm{~g} / \mathrm{mol}$ was purchased from Sigma-Aldrich [Darmstadt, Germany]. Scheme 1 displays the chemical formulas of PEG and PPG based reactants. Toluene was used as the extracting solvent for non-reacted molecules was supplied by SigmaAldrich. AMC-2 catalyst [Aerojet Chemicals, Rancho Cordova, CA], composed of $50 \%$ trivalent organic chromium complexes and 50\% phthalate esters was used to minimize possible epoxy homopolymerization. All obtained products were dried under vacuum at 40 ${ }^{\circ} \mathrm{C}$ for 48 hours before use.

\subsection{Preparation of comb-type grafted PEG-PPG Hydrogels}

Five different networks were prepared based on the initial molar concentrations of the reactive groups 
$\left[r=2\left[\mathrm{NH}_{2}\right]_{0} /[\mathrm{E}]_{0}\right]$, where $\mathrm{r}$ is the molar ratio of amine $\left[\mathrm{NH}_{2}\right]$ to epoxy groups.

Catalytic amount of AMC-2 catalyst (1 drop) was added to this composition as a catalytic inhibitor of side reactions. All reactants in the composition mixture were first stirred homogeneously at $100{ }^{\circ} \mathrm{C}$ for $15 \mathrm{~min}$ and then poured into silicon molds. In these molds, the reactions were performed under nitrogen atmosphere at $120{ }^{\circ} \mathrm{C}$ for $48 \mathrm{~h}$. The obtained gels based on hydrophobic Jeffamine ${ }^{\circledR}$ M2005 to PEG diepoxide mole ratio were labeled JM0, JM10, JM20, JM30, and JM40 as shown in Table 1.

At the end of this reaction phase, non-reacted soluble fractions in the hydrogel networks were removed via a triple extraction step using toluene. The final products were carefully dried first in open air and then at $40^{\circ} \mathrm{C}$ under vacuum for about $48 \mathrm{~h}$. The soluble fraction (SF) was calculated using the following equation:

$S F(\%)=\frac{w_{0}-w}{w_{0}} \times 100$

where, $W_{0}$ and $W$ are the weights of the hydrogels before and after purification, respectively.

FTIR spectrum of dried hydrogels was obtained using Shimadzu 8201 FT infrared spectrophotometer at a resolution of $4 \mathrm{~cm}^{-1}$ in the range of $4000-400 \mathrm{~cm}^{-1}$.

Table 1. Chemical composition of PEG-PPG based hydrogel with soluble fractions

\begin{tabular}{|c|c|c|c|c|c|c|c|}
\hline \multirow{2}{*}{$\begin{array}{l}\text { Hydrogel } \\
\text { Code }\end{array}$} & \multicolumn{2}{|c|}{ Diepoxy } & \multicolumn{2}{|c|}{ JM2005 } & \multicolumn{2}{|c|}{ JED600 } & \multirow{2}{*}{$\begin{array}{l}\text { SF } \\
\%\end{array}$} \\
\hline & $\mathrm{g}$ & $\mathrm{mmol}$ & $\mathrm{g}$ & $\mathrm{mmol}$ & $\mathrm{g}$ & $\mathrm{mmol}$ & \\
\hline JM0 & 1.00 & 2.00 & 0.00 & 0.00 & 0.53 & 1.00 & 6.29 \\
\hline JM10 & 1.00 & 2.00 & 0.41 & 0.20 & 0.47 & 0.90 & 12.20 \\
\hline JM20 & 1.00 & 2.00 & 0.84 & 0.40 & 0.42 & 0.80 & 24.23 \\
\hline JM30 & 1.00 & 2.00 & 1.25 & 0.60 & 0.37 & 0.70 & 31.99 \\
\hline JM40 & 1.00 & 2.00 & 1.67 & 0.80 & 0.32 & 0.60 & 39.60 \\
\hline
\end{tabular}

\subsection{Swelling analysis}

The swelling behavior of the synthesized hydrogels with respect to change in $\mathrm{pH}$ and temperature was evaluated by immersing weighted hydrogels into the different $\mathrm{pH}$ buffer solution of 2.5, 5.0, 7.4, and 10.0 as well as different temperatures from 4 to $50{ }^{\circ} \mathrm{C}$ for 24 $\mathrm{h}$. The ionic strength of all $\mathrm{pH}$ buffer solutions was adjusted to $0.1 \mathrm{M}$ beforehand. Once the swollen hydrogels reached equilibrium, they were separated from the buffer solution, blotted with filter paper and then measure accurately in triplicates and the average value recorded. The swelling ratio [SR] was subsequently calculated following the equation below.

$S R=\frac{W_{s}}{W_{d}}$

where, $W_{s}$ and $W_{d}$ are the weights of the equilibrium swollen and dried gels, respectively.

The dynamic swelling behaviors of the hydrogels were analyzed by calculating the change in SR as a function of time at $4{ }^{\circ} \mathrm{C}$ in $\mathrm{pH} 7.4$ buffer solutions. At regular time intervals, the hydrogel samples were removed from the buffer solutions, blotted, and weighed to calculate the water retention using the following equation:

$S R_{t}=\frac{W_{t}}{W_{d}}$

where, $W_{d}$ represents the weights of the dried samples and $W_{t}$ represents the weights of the swollen hydrogels at time $t$.

\subsection{Deswelling capacity}

The deswelling rate of the hydrogels was investigated using swollen samples in $\mathrm{pH} 7.4$ buffer solution at $4{ }^{\circ} \mathrm{C}$ for $24 \mathrm{~h}$ and then transferred to an oven of temperature $40{ }^{\circ} \mathrm{C}$. At this temperature, the weight difference of the hydrogels was gravimetrically determined at varying time intervals as described above. The water retention [WR] percentage was calculated using the equation below.

Water retention $=\frac{w_{t}-w_{d}}{w_{s}} \times 100$

where, $W_{s}$ represents the weights of equilibrium swollen hydrogels at $40{ }^{\circ} \mathrm{C}, W_{t}$ represents the weights of hydrogels at time $t$ and $W_{d}$ represents the weights of dried samples. 


\section{Results and discussion}

\subsection{Synthesis and characterization of PEG-PPG based comb-type grafted hydrogels}

Five different compositions of hydrogels were synthesized via ring-opening reactions by reacting Jeffamine $^{\circledR}$ M2005 and PEGDGE using Jeffamine ${ }^{\circledR}$ ED600 as the crosslinking agent. The schematic reaction processes are depicted in Scheme 1. The various hydrogel networks are formed by increasing the mole ratio of the monoamino-terminated polymer. A constant molar ratio of 1:2 was used between the amino and epoxy groups considering the reaction capability of one primary amines being able to bind with two epoxy rings. As observed in the reaction mechanism shown in Scheme 2, primary amines react with an epoxy moiety to form secondary amines followed by possible second reaction where another epoxy ring can be opened by secondary amines to form tertiary amine compounds. In addition, hydroxyl groups formed as intermediates during the ringopening reaction process may participate by reacting with epoxide rings as side reactions. Thus, the use of AMC-2 catalyst was incorporated as an inhibitor to eliminate side reactions generated by hydroxyl groups [27].

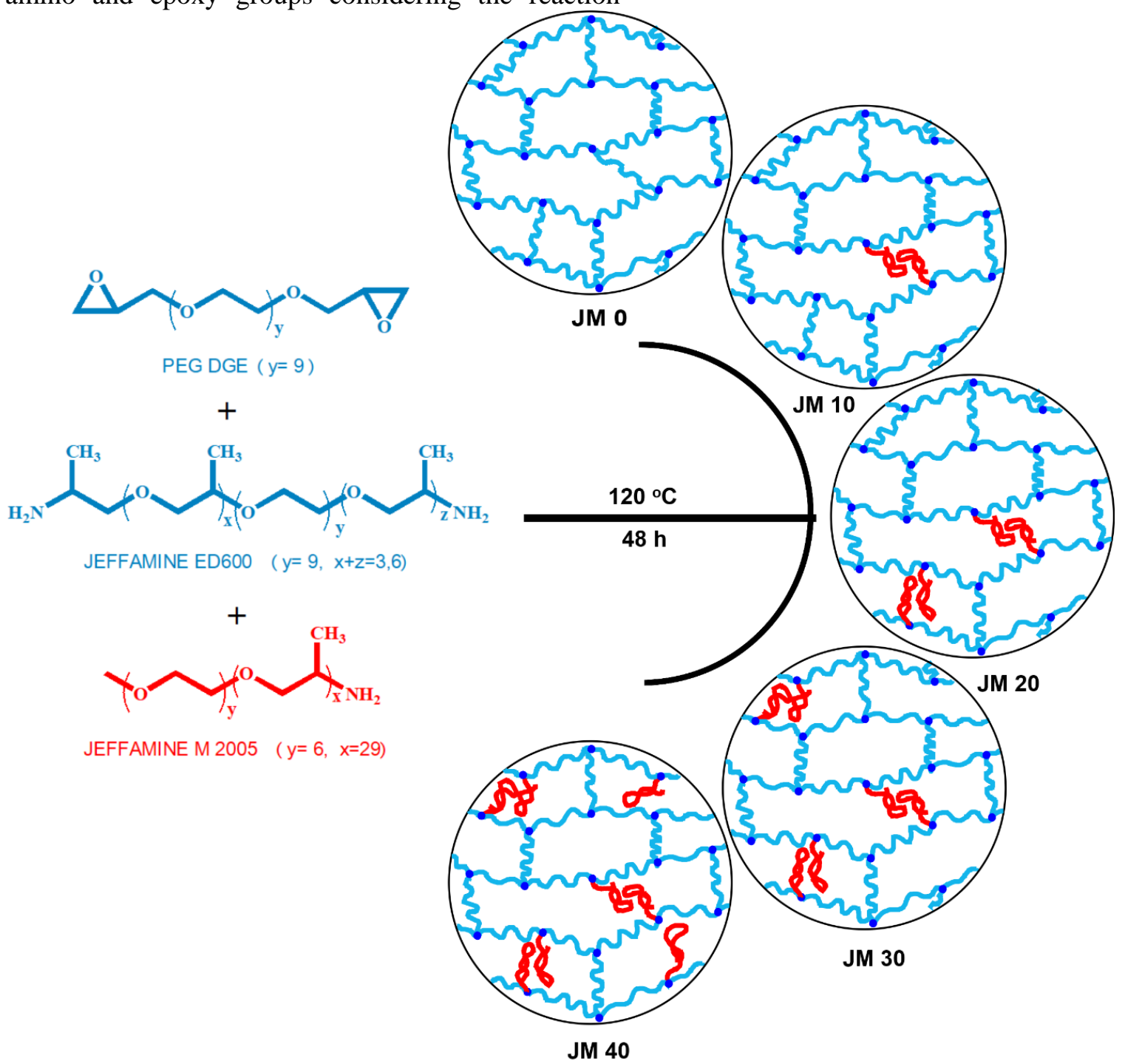

Scheme 1. Illustration of chemical reactions involved in the preparation of comb-type grafted PEG-PPG based hydrogels.

In general, during the preparation of such hydrogel networks, defects often exist described by loops and pendant links. These defects normally known as soluble fractions demonstrates negative effects during the characterization and application of the final product. Therefore after synthesis, it is essential for a suitable solvent to be used in the extraction of the comb-type grafted network, toluene was used as a suitable solvent to extract unreacted soluble PPG and PEG residues in the hydrogel by washing several times. For these hydrogels, an increase in the amount of Jeffamine M2005 increased the amount of soluble 
fractions from $6.3 \%$ to $39.6 \%$ for JM0 and JM40, respectively. This is attributed to the decreasing amount of crosslinker and the entanglement of high molecular weight Jeffamine M2005 in the hydrogel network [20].

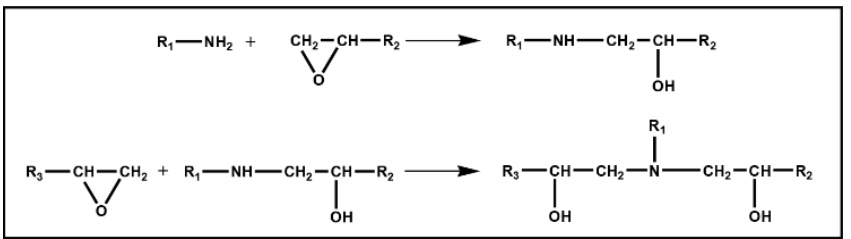

Scheme 2. Schematic reaction mechanism representation of primary amines with epoxy moieties in the formation of epoxy networks.

Fourier transform infrared [FTIR] spectroscopy was used to analyze the functionality of the hydrogels. Figure 1 depicts the FTIR spectra for varying ratio of PPG content for dried comb-type grafted hydrogels. The characteristic peaks at 846, 947, 1100, 1250, 1295, 1347 , and $1464 \mathrm{~cm}^{-1}$ were attributed to stretching vibrations for the polyether chains. The bands at 756 and $911 \mathrm{~cm}^{-1}$ were assigned to the typical stretching and vibrations of epoxy rings which disappeared after the reaction [28]. Increase in the amount of incorporated Jeffamine M2005 was confirmed by the increasing intensity of symmetrically deformed and asymmetrically spread peak of PPG methyl groups at 1373 and $2969 \mathrm{~cm}^{-1}$, respectively [6]. Also, the broad band observed at $3454 \mathrm{~cm}^{-1}$ relates to hydroxyl $[-\mathrm{OH}]$ groups formed during the ring-opening reaction process.

\subsection{Effect of contact time on the swelling capacity of hydrogels}

The effect of hydrogel swelling as a function of time was investigated at a constant $\mathrm{pH} 7.4$ and at a temperature of $4{ }^{\circ} \mathrm{C}$. The obtained results are illustrated in Figure 2. Swelling analysis performed at $4{ }^{\circ} \mathrm{C}$ was due to the cloud point temperature of Jeffamine ${ }^{\circledR}$ M2005 determined as $18{ }^{\circ} \mathrm{C}$ [29]. All synthesized hydrogels demonstrated to reach equilibrium swelling within $24 \mathrm{~h}$. Based on formulated samples, swelling capacity of hydrogels increased with increasing amount of Jeffamine ${ }^{\circledR}$ M2005. Therefore, the equilibrium swelling of the hydrogels were in the magnitude of JM40>JM30>JM20>JM10>JM0. Crosslinking density in hydrogels plays a vital role in their network stability. A gradual increase in the amount of Jeffamine $^{\circledR}$ M2005 decreased the crosslinking density of the hydrogels. However, hydrogel samples with high crosslinking density reached equilibrium swelling faster than lower crosslinked hydrogels due to the hydrophobic nature of
Jeffamine ${ }^{\circledR}$ M2005 that tend to slow water penetration into the hydrogel network.

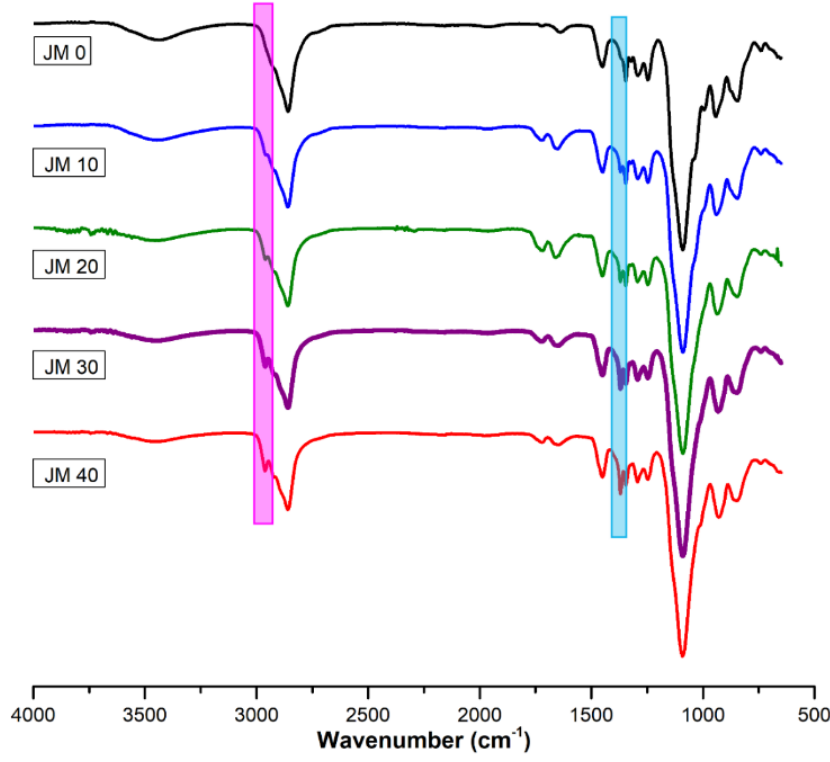

Figure 1. FTIR spectra of the prepared hydrogels.

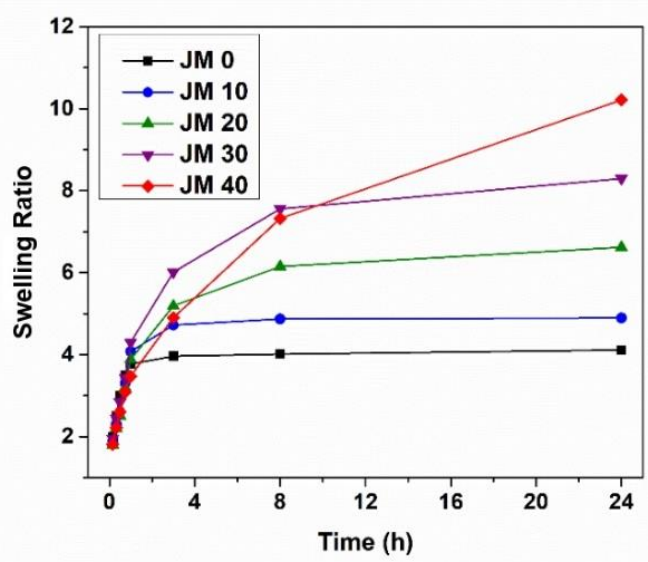

Figure 2. Swelling capacity of PEG-PPG based hydrogels as a function of time at $4{ }^{\circ} \mathrm{C}$ and $\mathrm{pH} 7.4$ buffer solution.

\subsection{Effect of $\mathrm{pH}$ on the swelling capacity of hydrogels}

The effect of $\mathrm{pH}$ on equilibrium swelling of the hydrogels was evaluated at varying $\mathrm{pH}$ of $2.5,5.0,7.4$ and 10.0 at constant temperature of $4{ }^{\circ} \mathrm{C}$. The deduced results are summarized in Figure 3. The prepared hydrogels are composed of cationic amine components such as tertiary amines or unreacted secondary/primary amines. These functional groups play an important role in the swelling capacities of the hydrogels with respect to medium $\mathrm{pH}$. Maximum swelling capacities were determined at $\mathrm{pH} 5.0$ as $4.69,6.31,7.93,10.73$, and $12.22 \mathrm{~g} / \mathrm{g}$ for JM0, JM10, JM20, JM30, and JM40, respectively. Considering the high acidity of $\mathrm{pH} 2.5$, 
the obtained lower swelling capacities as compared to pH 5.0 for all hydrogels was attributed to the excess presence of $\mathrm{H}^{+}$ions in solution that in tend reduced the osmotic pressure difference between outside and inside of the hydrogels [30], thus directly decreasing the swelling ability of the hydrogels. By the increasing $\mathrm{pH}$ to 7.4 , swelling capacity of the hydrogels gradually decreased to $4.11,4.89,6.61,8.29$, and $10.21 \mathrm{~g} / \mathrm{g}$ for JM0, JM10, JM20, JM30, and JM40, respectively. This decrease was related to decreasing charge density on hydrogels as $\mathrm{pH}$ increases thereby decreasing electrostatic interaction between hydrogels and water molecules [31]. However, swelling ratios of hydrogels did not decrease as much as before with increasing the $\mathrm{pH}$ from 7.4 to 10.0 due to the low electrostatic interaction change.

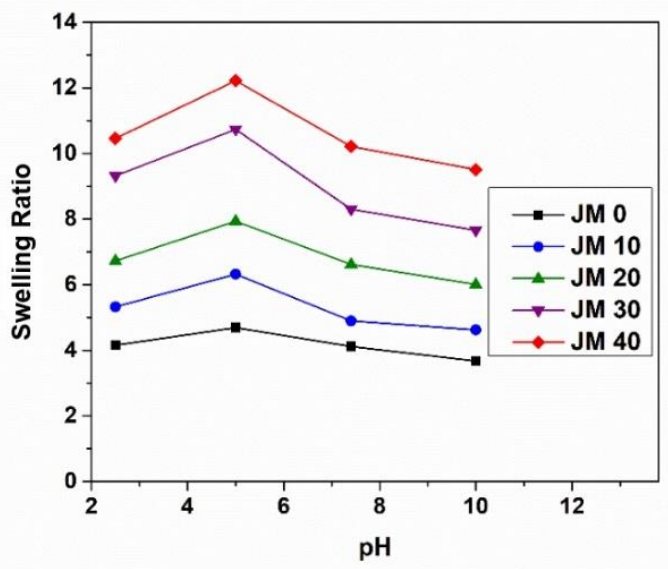

Figure 3. Swelling capacity of PEG-PPG based hydrogels at different $\mathrm{pH}$ and constant temperature of $4{ }^{\circ} \mathrm{C}$.

\subsection{Temperature response of hydrogels based on swelling analysis}

The thermo-responsive properties of the prepared comb-type grafted hydrogels were evaluated by determining swelling capacity at different temperature values ranging from 4 to $50{ }^{\circ} \mathrm{C}$ at constant $\mathrm{pH} 5.0$ and 7.4. Based PPG-containing hydrogels, The decrease in swelling capacity of hydrogels with temperature indicates that they are thermo-sensitive [
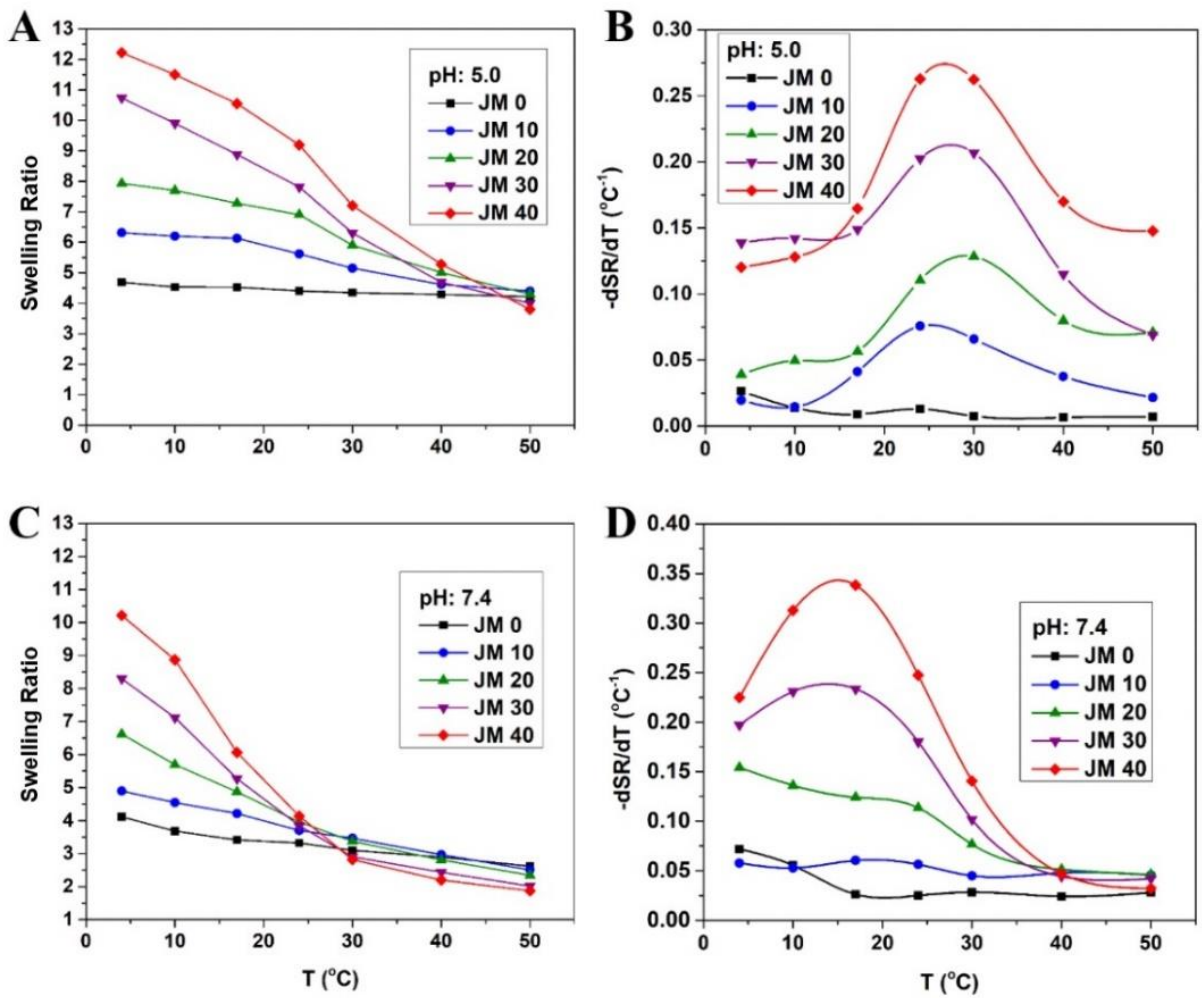

Figure 4. The swelling capacity of PEG-PPG based hydrogels as a function of temperature change A] original curves at $\mathrm{pH}$ 5.0, B] derivative curves at $\mathrm{pH} 5.0, \mathrm{C}$ ] original curves at $\mathrm{pH} 7.4$, and $\mathrm{D}$ ] derivative curves at $\mathrm{pH}$ 7.4. 


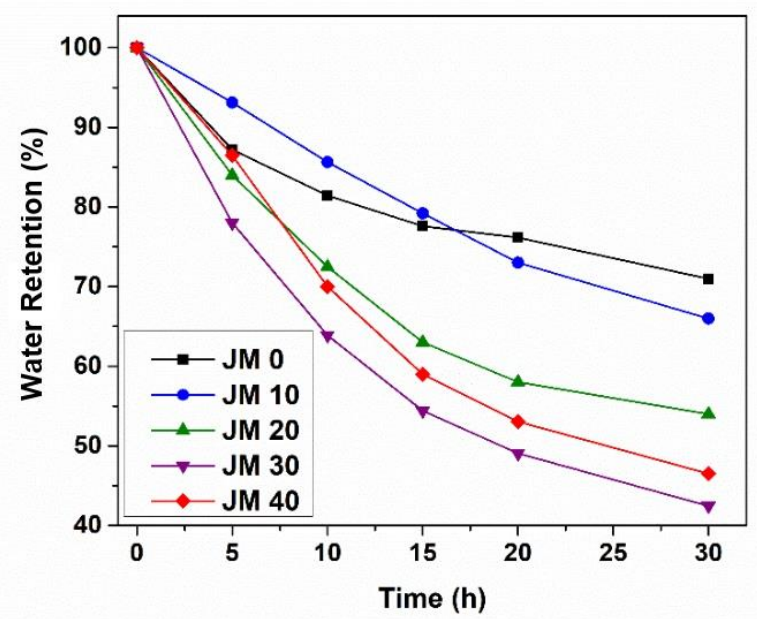

Figure 5. Water retention dependence on the deswelling time of PEG-PPG based hydrogels as the water temperature changes from 4 to $40{ }^{\circ} \mathrm{C}$.

\section{Conclusions}

Crosslinked PEG-PPG thermo- and $\mathrm{pH}$-sensitive hydrogels based on Jeffamine ${ }^{\circledR}$ M2005, Jeffamine ${ }^{\circledR}$ ED600, and PEGDGE were synthesized and characterized physico-chemically. The thermo- and $\mathrm{pH}$-responsive behavior of hydrogels were evidenced via appropriate swelling measurements. Jeffamine ${ }^{\circledR}$ M2005 induced interesting thermosensitive properties in the hydrogels due to its preponderantly intramolecular or intermolecular interactions and hydrophobic character. At high temperature, the swelling capacity of the hydrogels was mainly controlled by PPG concentration, which indicated an increase in swelling with increasing PPG hydrophobic content. While at lower temperature, the swelling ability was majorly controlled by crosslinking density that demonstrated the hydrogels swelling increased with decreasing crosslinker ratio. Comparatively, deswelling analysis showed that JM30 deswelled faster than JM40 due to its higher crosslinking density and suitable thermo-responsive properties. Thus, depicting JM30 as the most suitable thermo-responsive hydrogel with highest sensitivity and lower soluble fractions than JM40. In addition, VPTT of the PEG-PPG based hydrogels demonstrated to be in close agreements with the phase separation temperature of Jeffamine ${ }^{\circledR}$ M2005 at $\mathrm{pH}$ 7.4. In conclusion, the prepared dual sensitive PEG-PPG hydrogels have chance for interesting potential applications in controlled drug delivery like our previous study [26]. Further studies are in development to appreciate their performances in this field.

\section{Conflict of Interests}

The authors declare no conflict of interest.

\section{Acknowledgements}

A great thanks to the Hustsman Corp. for the gift of the jeffamine chemicals.

\section{References}

[1] Ahmed EM., Hydrogel: Preparation, characterization, and applications: A review. Journal of advanced research, 6(2) (2015) 105-121.

[2] Peppas NA, Hilt JZ, Khademhosseini A, Langer R. Hydrogels in biology and medicine: from molecular principles to bionanotechnology, Advanced Materials, 18(11) (2006) 1345-1360.

[3] Ratner BD, Hoffman AS, Schoen FJ, Lemons JE. Biomaterials science: an introduction to materials in medicine: Elsevier; 2004.

[4] Calik MK, Ozdemir M., Synthesis, characterization and, swelling behavior of semi-IPN nanocomposite hydrogels of alginate with poly (Nisopropylacrylamide) crosslinked by nanoclay, Journal of Applied Polymer Science, 133(12) (2016).

[5] Kocak G, Tuncer C, Bütün V., pH-Responsive polymers, Polymer Chemistry, 8(1) (2017) 144-176.

[6] Anghelache A, Teodorescu M, Stănescu PO, Drăghici C, Vuluga DM. Novel crosslinked thermoresponsive hydrogels with controlled poly (ethylene glycol) - poly (propylene glycol) multiblock copolymer structure, Colloid and Polymer Science, 292(4) (2014) 829-638.

[7] Pahimanolis N, Sorvari A, Luong ND, Seppälä J. Thermoresponsive xylan hydrogels via coppercatalyzed azide-alkyne cycloaddition, Carbohydrate Polymers, 102 ( 2014) 637-644.

[8] Erdem A, Ngwabebhoh FA, Yildiz U., Synthesis, characterization and swelling investigations of novel 
polyetheramine-based hydrogels, Polymer Bulletin 74(3) (2017) 873-893.

[9] Saito S, Otsuka T., Dissolution of some polymers in aqueous solutions of urea, of its related compounds, and of tetraalkylammonium salts, Journal of Colloid and Interface Science, 25(4) (1967) 531-536.

[10] Brown C., Water soluble polymers, New York: Elsevier, 1974; pp. 424

[11] Ma W-D, Xu H, Wang C, Nie S-F, Pan W-S., Pluronic F127-g-poly (acrylic acid) copolymers as in situ gelling vehicle for ophthalmic drug delivery system, International Journal of Pharmaceutics, 350(1-2) (2008) 247-256.

[12] Gioffredi E, Boffito M, Calzone S, Giannitelli SM, Rainer A, Trombetta M, et al., Pluronic F127 hydrogel characterization and biofabrication in cellularized constructs for tissue engineering applications, Procedia Cirp., 49 (2016) 125-32.

[13] Erdem A, Ngwabebhoh FA, Yildiz U., Fabrication and characterization of soft macroporous Jeffamine cryogels as potential materials for tissue applications, RSC Advances, 6(113) (2016) 11187211881.

[14] Sharma RK, Shah U., Aggregation Behavior of PEO-PPO-PEO Tri-Block Copolymer (Pluronic $\AA$ L64) in Nonionic Surfactant Additives Environment, Tenside Surfactants Detergents, 51(3) (2014) 274-281.

[15] Singh V, Khullar P, Dave PN, Kaur N. Micelles, mixed micelles, and applications of polyoxypropylene (PPO)-polyoxyethylene (PEO)polyoxypropylene (PPO) triblock polymers, International Journal of Industrial Chemistry. 41(1) (2013) 12-19.

[16] Sosnik A, Cohn D, Román JS, Abraham GA., Crosslinkable PEO-PPO-PEO-based reverse thermo-responsive gels as potentially injectable materials, Journal of Biomaterials Science, Polymer Edition 14(3) (2003) 227-239.

[17] Niu G, Djaoui AB, Cohn D., Crosslinkable PEOPPO-PEO triblocks as building blocks of thermoresponsive nanoshells, Polymer, 52(12) (2011) 2524-2530.

[18] Lee S-Y, Tae G., Formulation and in vitro characterization of an in situ gelable, photopolymerizable Pluronic hydrogel suitable for injection, Journal of Controlled Release. 119(3) (2007) 313-319.

[19] Kim MR, Park TG., Temperature-responsive and degradable hyaluronic acid/Pluronic composite hydrogels for controlled release of human growth hormone, Journal of Controlled Release, 80(1-3) (2002) 69-77.

[20] Krakovský I, Cayuela JC, i Serra RS, SalmerónSánchez M, Dodda JM. Epoxy networks and thermosensitive hydrogels prepared from $\alpha, \omega$ diamino terminated polyoxypropylene and polyoxyethylene bis (glycidyl ether), European Polymer Journal, 55 ( 2014) 144-152.

[21] Epoxy formulations using Jeffamine ${ }^{\circledR}$ Polyetheramines, www.huntsman.com.

[22] Krakovský I, Székely NK., SANS and DSC study of water distribution in epoxy-based hydrogels. European polymer journal, 47(12) (2011) 2177-88.

[23] Ribelles JLG, Sanchez MS, de la Osa LT, Krakovský I. Thermal transitions in $\alpha, \omega$-diamino terminated poly (oxypropylene)-block-poly (oxyethylene)-block-poly (oxypropylene) aqueous solutions and their epoxy networks, Journal of NonCrystalline Solids, 351(14-15) (2005) 1254-1260.

[24] Mocanu G, Souguir Z, Picton L, Le Cerf D., Multiresponsive carboxymethyl polysaccharide crosslinked hydrogels containing Jeffamine sidechains. Carbohydrate Polymers, 89(2) (2012) 578585.

[25] Marques NdN, Balaban RdC, Halila S, Borsali R. Synthesis and characterization of carboxymethylcellulose grafted with thermoresponsive side chains of high LCST: The high temperature and high salinity self-assembly dependence, Carbohydrate Polymers, 184 (2018) 108-117.

[26] Erdem A., Preparation and characterization of rapid temperature responsive cationic comb-type grafted POE-POP based hydrogel as prospective excellent actuators/sensors, Colloids and Surfaces A: Physicochemical and Engineering Aspects (2020) 125523-125529.

[27] Esen H, Küsefoğlu S, Wool R., Photolytic and freeradical polymerization of monomethyl maleate esters of epoxidized plant oil triglycerides, Journal of Applied Polymer Science, 103(1) (2007) 626-633.

[28] Teodorescu M, Cursaru B, Stanescu P, Draghici C, Stanciu ND, Vuluga DM., Novel hydrogels from diepoxy-terminated poly (ethylene glycol) s and aliphatic primary diamines: synthesis and equilibrium swelling studies, Polymers for Advanced Technologies, 20(12) (2009) 907-915.

[29] Wilfert S, Iturmendi A, Henke H, Brüggemann O, Teasdale I, Thermoresponsive PolyphosphazeneBased Molecular Brushes by Living Cationic Polymerization, Macromolecular Symposia, Wiley Online Library, (2014): 9-18

[30] Gunasekaran S, Wang T, Chai C., Swelling of pHsensitive chitosan-poly (vinyl alcohol) hydrogels, Journal of Applied Polymer Science. 102(5) (2006) 4665-4671.

[31] Deen GR, Mah CH., Influence of external stimuli on the network properties of cationic poly (N-acryloylN'-propyl piperazine) hydrogels, Polymer, 89 (2016) 55-68.

[32] Gehrke SH., Synthesis, equilibrium swelling, kinetics, permeability and applications of 
environmentally responsive gels, Responsive gels: volume transitions II: Springer, (1993); p. 81-144.

[33] Turan E, Demirci S, Caykara T., Thermo-and pHinduced phase transitions and network parameters of poly (N-isopropylacrylamide-co-2-acrylamido-2methyl-propanosulfonic acid) hydrogels, Journal of Polymer Science Part B: Polymer Physics, 46(16) (2008) 1713-24.

[34] Liu Y-Y, Fan X-D., Synthesis and characterization of $\mathrm{pH}$-and temperature-sensitive hydrogel of $\mathrm{N}$ isopropylacrylamide/cyclodextrin based copolymer, Polymer, 43(18) (2002) 4997-5003.
[35] Van Durme K, Van Mele B, Loos W, Du Prez FE., Introduction of silica into thermo-responsive poly (N-isopropyl acrylamide) hydrogels: A novel approach to improve response rates, Polymer, 46(23) (2005) 9851-9862.

[36] Cates RS., Influence of crosslink density on swelling and conformation of surface-constrained Poly (N-isopropylacrylamide) hydrogels, Graduate thesis, 15 (2010) 15-18. 